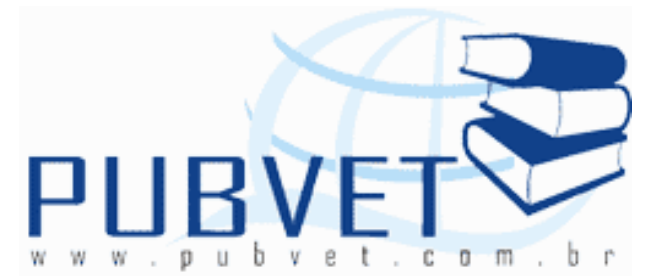

PUBVET, Publicações em Medicina Veterinária e Zootecnia.

\title{
Efeito da suplementação de calor para leitões recém-nascidos
}

Fernando Gomes de Castro Júnior ${ }^{1}$, José Carlos de M. Camargo², Fábio Enrique Lemos Budiño ${ }^{1}$

1.Pesquisador Científico, Instituto de Zootecnia/CPDZD/APTA/SAA

(castrojr@iz.sp.gov.br/fbudino@iz.sp.gov.br);

2.Pesquisador Científico, Unidade de P\&D de Itapeva

DDD/APTA/SAA(upditapeva@apta.sp.gov.br)

\section{Resumo}

Durante o verão, 24 porcas primíparas (Duroc Jersey, Piau Canastra e Wessex Sanddleback) e suas respectivas leitegadas foram utilizadas para avaliar o calor suplementar (lâmpada de 250 watts infravermelha). A lâmpada foi removida da área de proteção (escamoteador) três dias após o parto. As maternidades pertenciam a Unidade de Pesquisa e Desenvolvimento de Itapeva, localizada a 684 metros de altitude, à latitude de $23^{\circ} 58^{\prime} 56^{\prime \prime}$ sul e à longitude de $48^{\circ} 52^{\prime} 32^{\prime \prime}$ oeste. O ambiente da maternidade não foi controlado artificialmente e, a média mensal das temperaturas do ar foi de $21,9^{\circ} \mathrm{C}$ e $76 \%$, respectivamente. O delineamento experimental adotado foi o de blocos ao acaso, com 4 repetições e 6 tratamentos em esquema fatorial $3 \times 2$, os fatores foram: raças (Duroc Jersey, Wessex Saddleback e Piau Canastra) e fonte de calor (com e sem). Os resultados demonstraram que: 1) Não houve efeito significativo $(P<0,05)$ para o numero de leitões sobreviventes até o $5^{\circ}$ 
dia após o nascimento, entre e dentro das raças estudadas com ou sem calor suplementar; 2) As leitegadas pertencentes a raça nativa, apresentaram uma tendência de menor ganho em peso até o $5^{\circ}$ dia após o nascimento do que as exóticas, entretanto, somente o ganho em peso das leitegadas Wessex, foi significativamente $(P<0,05)$, maior do que o ganho de peso das leitegadas Piau; 3) As leitegadas das raças exóticas (Duroc e Wessex), que receberam calor suplementar, apresentaram maior ganho em peso até o $5^{\circ}$ dia após 0 nascimento e este ganho foi significativo ao nível de $5 \%$ de probabilidade e 4) As leitegadas da raça nativa (Piau), com ou sem calor suplementar não apresentaram diferenças significativas $(P<0,05)$, para ganho em peso até o $5^{\circ}$ dia após o nascimento.

Palavras-chave: Duroc Jersey, Piau Canastra, Wessex Saddleback, primiparas

\section{Effect of supplemental heat for baby pigs}

\section{Abstract}

During the summer, 24 sows (first weaning), from the breeds, Duroc Jersey, Wessex Saddleback and "Piau Canastra", and his litters were used to evaluate the effects of supplemental heat (lamp 250 watts infra red brood). Heat lamp was removed from the farrowing area at 3 days post partum. The farrowing houses were located in Itapeva Recherché and Development Unit (Swine Experimental Station), at 684 meters above the sea, $23^{\circ} 58^{\prime} 56^{\prime \prime}$, sud latitude, and $48^{\circ} 52^{\prime} 32^{\prime \prime}$ west. Longitude. There was no artificial temperature control in forrowing house and the means of temperature and relative humidity were $23^{\circ} \mathrm{C}$ and $76 \%$, respectively. A complete randomized design was utilized with 4 replicates and 6 treatments in $3 \times 2$ factorials. The factors were: breeds (Duroc, Wessex and Piau) and supplemental heat (with and without infra red lamp). The results showed that: 1) No significant differences at the $5 \%$ probability level were observed in baby pig survivals up to 5 days after birth, between and inside breeds, with or without supplemental heat; 2) The litters from native breed (Piau Canastra), presented a trend to have lower weight 
gain up to 5 days after birth than the exotics, however, only Wessex breed weight gain litters was significantly $(P<0,05)$, heavier than the Piau Canastra breed weight gain litters; 3) The litters from exotics breeds (Duroc and Wessex), that received supplemental heat presented move weight gain up to 5 days after birth than those did not received and this gain was significant at the $5 \%$ probability level; and 4) The differs from native breed with or without supplemental heat did not presented a significant $(P<0,05)$ from the weight gain up to 5 days after birth.

Keywords: Duroc Jersey, Piau Canastra, Wessex Saddleback, first weaning sows and radiant heat.

\section{INTRODUÇÃO}

Uma das mudanças mais evidentes na suinocultura brasileira, e mundial, é a tendência linear observada na diminuição do número de sistemas de produção em funcionamento, paralela a um aumento no número de animais produzidos em cada um desses sistemas. O comportamento cíclico do mercado de suínos exige que se busque êxito e lucratividade na produção, vinculado a variáveis como disponibilidade financeira, mão de obra especializada, qualidade produtiva e reprodutiva dos animais e manejo empregado. Cada uma das variáveis tem sua importância, sendo decisivo considerá-las de forma interdisciplinar (Mendes 2005).

O fator econômico e principalmente o investimento inicial, é importante, podendo-se minimizá-lo com alternativa nas técnicas empregadas, que possibilitarão melhora no desempenho do plantel ao alcançarem-se melhores valores na relação custo-benefício (Reis, 1995).

Fatores ambientais externos e o microclima dentro das instalações exercem efeitos diretos e indiretos sobre a produção de suínos, acarretando a redução da produtividade, com conseqüentes prejuízos econômicos à produção (Mendes 2005) A maternidade é o setor mais detalhado e complexo a ser projetado, pois os leitões recém nascidos requerem altas temperaturas 
CASTRO JÚNIOR, F.G.; CAMARGO, J.C.M. e BUDIÑO, F.E.L. Efeito da suplementação de calor para leitões recém-nascidos. PUBVET, Londrina, V. 5, N. 28, Ed. 175, Art. 1178, 2011.

ambientais para prevenir excessivas perdas de calor dos seus corpos, porém temperaturas ambientais mais baixas são desejáveis para o conforto das matrizes. Portanto, é comum a adoção de práticas que promovam calor localizado para os leitões enquanto se mantêm temperaturas inferiores para as matrizes nas maternidades.

Os efeitos do resfriamento durante as primeiras quatro horas após o nascimento dos leitões foram investigados por Newland et alii (1952) e concluíram que: a queda da temperatura retal em leitões de peso médio de 1 $\mathrm{kg}$ foi de $2,7^{\circ} \mathrm{C}$ e em leitão de $0,6 \mathrm{~kg}$ foi de $5,2^{\circ} \mathrm{C}$. A maior queda ocorreu 20 minutos após o parto. A uma temperatura ambiente variando de 15 à $24{ }^{\circ} \mathrm{C}$, a temperatura retal normal foi atingida em dois dias, entretanto demorou 10 dias quando a temperatura ambiente variou de $-3,5$ à $2^{\circ} \mathrm{C}$. Os leitões resfriados mostraram elevação de açúcar sanguíneo (menos acentuado, quando em jejum) de 73 para $100 \mathrm{mg} / 100 \mathrm{ml}$. Os leitões em jejum e em criadeiras aquecidas apresentaram concentração de açúcar sanguíneo de $50 \mathrm{mg} / 100 \mathrm{ml}$.

Pomeroy (1953), relatou como sintomas provocados pelo resfriamento: anorexia, respiração superficial, descoordenação motora e coma. Esses sintomas foram reversíveis pelo aquecimento. A temperatura retal dos leitões durante o parto foi de $40,5^{\circ} \mathrm{C}$ e poucos minutos após de $37,5^{\circ} \mathrm{C}$. Durante a vida uterina, a temperatura corporal do leitão é bastante alta e constante, em comparação com a vida extra uterina. Ao nascer, o leitão está neurologicamente bem desenvolvido, porém fisiologicamente ainda é considerado imaturo e sua capacidade de controlar eficientemente a temperatura corporal está pouco desenvolvida, não podendo compensar imediatamente a intensa perda de calor logo após o parto (Sobestiansky et alii, 1998). A temperatura corporal do recém-nascido cai de 1,7 a $6,7^{\circ} \mathrm{C}$ (em média $2,2^{\circ} \mathrm{C}$ ), logo após o parto. O tempo que o leitão leva para alcançar novamente valores fisiológicos normais de temperatura corporal depende 
CASTRO JÚNIOR, F.G.; CAMARGO, J.C.M. e BUDIÑO, F.E.L. Efeito da suplementação de calor para leitões recém-nascidos. PUBVET, Londrina, V. 5, N. 28, Ed. 175, Art. 1178, 2011.

diretamente da temperatura ambiente, de seu peso corporal e do momento em que começa a mamar (Bäckström \& Curtis, 1981).

A hipoglicemia e exaustão de glicogênio foi constatada por Mount $(1959,1969)$ e a queda de temperatura ambiente incrementou a apreensão de oxigênio. Entretanto, os leitões neonatos não dependem exclusivamente de carboidratos para seu metabolismo energético. O aumento da taxa metabólica do leitão se deve ao fato do animal ter que usar grande parte de sua produção de energia para se manter aquecido, em vez de usá-la para o crescimento, piorando sua taxa de conversão. Além disso, essa perda no crescimento também limita o desenvolvimento da gordura, a qual, como camada subcutânea, aumenta o isolamento térmico do animal (Blair et alii,1976).

Os efeitos do resfriamento em leitões das raças domesticadas e em leitões selvagens do Tennessee foram comparados por Foley et alii (1970). Embora, os leitões selvagens fossem menores, eles foram mais termoestáveis com 6 horas de vida do que os leitões domesticados. Isso foi devido à proteção de um espesso manto piloso. Contudo, os leitões selvagens resfriados, consumiram mais oxigênio e geraram mais energia para manter a temperatura corporal.

Quando a temperatura ambiental é muito baixa, o recém-nascido perde calor e sua temperatura corporal cai rapidamente. Isso se deve, não só à incapacidade de regular eficientemente sua temperatura corporal, mas também ao fato de o leitão apresentar um revestimento de cerdas relativamente espaçadas, não podendo impedir o fluxo de calor através da pilo ereção, e por não possuir a camada de tecido gorduroso subcutâneo, que reduz o fluxo de calor desde os vasos sanguíneos até a superfície da pele (Simmons, 1976).

Segundo Concellon Martinez (1965), o leitão que nasce mais pesado é mais resistente do que o pequeno e delgado. Também, o gordo resiste melhor ao frio, existindo aí uma relação entre peso e a sua resistência. Essas conclusões foram extraídas de um ensaio, em que os leitões foram criados em temperaturas que variavam de 7 à $15^{\circ} \mathrm{C}$. Em temperatura de $4,5^{\circ} \mathrm{C}$ os leitões 
CASTRO JÚNIOR, F.G.; CAMARGO, J.C.M. e BUDIÑO, F.E.L. Efeito da suplementação de calor para leitões recém-nascidos. PUBVET, Londrina, V. 5, N. 28, Ed. 175, Art. 1178, 2011.

mais débeis não resistiram e os mais robustos mantiveram-se bem. À $17^{\circ} \mathrm{C}$, abaixo de zero, os leitões robustos resistiram até 72 horas após o nascimento, sem se congelar.

O frio contínuo ou intermitente aumenta a suscetibilidade dos leitões a infecções enterotoxigênicas de Escherichia coli e ao vírus da gastroenterite. Essa redução da resistência é causada, provavelmente, por mudanças na função imune induzidas pelo estresse. O aumento do cortisol no plasma, provocado por resfriamento, é um importante indicador fisiológico, podendo causar essas mudanças na resistência dos leitões às doenças infecciosas. Dependendo da intensidade da perda de calor, ocorre também morte por hipoglicemia ou predisposição à morte por esmagamento (Kelly, 1982).

Leitões em grupo tiveram maior facilidade no controle da temperatura e 0 incremento do consumo de oxigênio foi verificado em temperaturas abaixo de $30^{\circ} \mathrm{C}$ (Mount, 1959;1960). A perda de calor por evaporação é similar nas temperaturas de 20 e $30^{\circ} \mathrm{C}$ (Mount,1962). Entretanto, aumentando essa temperatura (fornecendo calor suplementar) a taxa de calor dissipado pela evaporação que é uma parte da perda de calor aumenta e a perda de calor total é sensível e diminui quando a temperatura ambiente se eleva. A perda de calor sensível se da através da radiação, condução, e convecção. Sob uma temperatura ambiente em torno de $20^{\circ} \mathrm{C}, 42 \%$ do calor sensível perdido pelos leitões alojados em piso de concreto, ocorre via radiação, $42 \%$ via convecção e $16 \%$ condução. A $30^{\circ} \mathrm{C}$ as perdas foram, respectivamente, $49 \%$ radiante, $34 \%$ convectivo e $17 \%$ condutivo (Mount,1964).

Segundo Butchbaker \& Shanklin (1964), trabalhando com leitões suspensos em cordas de nylon (anulando o fluxo condutivo), concluíram que $2 / 3$ do calor sensível perdido deu-se por radiação e $1 / 3$ por convecção, quando a temperatura ambiente foi em torno de $20^{\circ} \mathrm{C}$ e, a $30^{\circ} \mathrm{C}$ as perdas foram $3 / 4$ por radiação e $1 / 4$ por convecção Os autores constataram que, quando a temperatura ambiente baixa de $30^{\circ} \mathrm{C}$ para $20^{\circ} \mathrm{C}$, a perda de calor dos leitões neonatos aumenta em $100 \%$. Por outro lado, talvez a umidade relativa do ar afete o fluxo condutivo, pois ele influencia a densidade, a viscosidade e/ou o 
CASTRO JÚNIOR, F.G.; CAMARGO, J.C.M. e BUDIÑO, F.E.L. Efeito da suplementação de calor para leitões recém-nascidos. PUBVET, Londrina, V. 5, N. 28, Ed. 175, Art. 1178, 2011.

calor especifico do ar, determinando o coeficiente de convecção do meio. Paradoxalmente, a umidade do ambiente é mais importante como fator determinante da perda de calor através da convecção, do que através do fluxo evaporativo no caso de leitões recém-nascidos. Após a evaporação do liquido amniótico ou de sua remoção, a perda de calor sensível (evaporação) ocorre quase que inteiramente pelo trato respiratório (Curtis, 1970).

Os suínos, por suas características fisiológicas, possuem dificuldades de se adaptar às flutuações térmicas ambientais e a faixa de temperatura para seu conforto varia com a idade. Inglaterra (1963) recomenda para leitões recém-nascidos a seguinte faixa de temperatura: 24 à $27^{\circ} \mathrm{C}$, já para Comberg (1966) a temperatura ideal é de 32 a $30^{\circ} \mathrm{C}$ para leitões de zero a duas semanas de vida; de 28 a $25^{\circ} \mathrm{C}$ para leitões de três a quatro semanas; e 18 a $15^{\circ} \mathrm{C}$ para leitões com mais de quatro semanas de vida. Enquanto que a temperatura critica para leitões com base nas taxas metabólicas é em torno de $34^{\circ} \mathrm{C}$ (Curtis 1970)

O leitão recém-nascido possui os sistemas de termorregulação e imunitário pouco desenvolvidos, tornando-se sensível às temperaturas ambientais baixas. Nestas condições o leitão reduz sua atividade motora e, conseqüentemente, diminui a ingestão de colostro, acarretando maior incidência de doenças, maior número de leitões esmagados e alta taxa de refugos na desmama, sendo necessário alguns cuidados especiais. A regra básica é fornecer aos leitões um ambiente limpo, desinfetado, seco e aquecido $\left(32^{\circ} \mathrm{C}\right)$. O que significa investir em piso adequado e sistemas de aquecimento (Perdomo,1995).

Taylor et alii (1952), estudaram os fundamentos dos raios infravermelhos como fonte de aquecimento de leitões recém-nascidos. A lâmpada utilizada foi de 250 watts R-4 infravermelha, a altura de $90 \mathrm{~cm}$. Aquecendo uma superfície de $60 \mathrm{~cm}^{2}$ e proporcionando $212,5 \mathrm{kcal} / \mathrm{h}$. Constataram que os leitões deixaram de apresentar os sintomas de resfriamento (anorexia, convulsões, coma e conseqüentemente morte) quando 
CASTRO JÚNIOR, F.G.; CAMARGO, J.C.M. e BUDIÑO, F.E.L. Efeito da suplementação de calor para leitões recém-nascidos. PUBVET, Londrina, V. 5, N. 28, Ed. 175, Art. 1178, 2011.

receberam calor suplementar. Determinaram a seguinte equação: $Q=1,5-$ 0,033T, onde $\mathrm{Q}=$ nível de intensidade de calor a suplementar, expresso em $\mathrm{Btu} / \mathrm{in}^{2} / \mathrm{h}, \mathrm{T}=$ temperatura ambiente em graus Fahrenheit.

Concellon Martinez (1965), recomenda prover o leitão de boa cama e drenar o piso, pois o concreto úmido produziu um incremento de $50 \%$ a mais de perda de calor em relação ao seco. Curtis (1970), relatou que leitões alojados em piso de plástico $(2,5 \mathrm{~cm}$ de espessura), perdem $1 / 6$ a mais de calor para o piso do que quando este é de concreto $(2,5 \mathrm{~cm})$, e este $1 / 3$ a mais em relação ao de madeira $(1,27 \mathrm{~cm})$. A cama de palha $(2,5 \mathrm{~cm})$ reduz a perda de calor para o piso (fluxo condutivo) de $40 \%$ em relação ao concreto despido, cavaco de madeira (maravalha ou cepilho) com 2,5 cm de espessura, reduz a perda de calor em $66 \%$. A incorporação de outros materiais isolantes aos pisos foram pouco satisfatórios. Motte et alii (1971), constataram que a utilização de calor suplementar proporcionou 2,5 leitões a mais por leitegada.

Adams, Baker e Jensen (1978) utilizaram como fonte de calor suplementar uma lâmpada de 250 watts e estudaram a necessidade da fonte de até $03^{\circ}, 6^{\circ}$, e $21^{\circ}$ dia após o parto durante a primavera e o verão. Não obtiveram diferenças significativas ao nível de $5 \%$ de probabilidade para ganho de peso, eficiência alimentar e número de leitões sobreviventes. A temperatura ambiente foi mantida à $21^{\circ} \mathrm{C}$. Segundo Zhang \& Xin (2000), existem duas formas típicas de aquecimento localizado para os leitões, sendo elas o calor radiante (comumente gerado por lâmpadas) e o calor de superfície condutivo (obtido nos pisos térmicos). Embora a maioria dos produtores de suínos na América do Norte e do Sul utilizem sistemas de aquecimento por lâmpadas, o sistema de aquecimento por superfície, está ganhando maior aceitação atualmente.

Mendes (2005) estudou três condições distintas de manejo da ventilação natural: cortina totalmente aberta, semi-aberta e totalmente fechada. Concluiu que os diferentes manejos da cortina em salas de maternidade para produção intensiva de suínos influenciaram significativamente o ambiente térmico resultante, afetando a distribuição da 
temperatura, umidade relativa e velocidade do vento no interior da sala de maternidade, a distribuição da temperatura de superfície dos pisos dos escamoteadores aquecidos por pisos térmicos e lâmpadas incandescentes e a temperatura de pele das matrizes.

O objetivo do presente ensaio foi estudar os efeitos de calor suplementar na forma radiante em escamoteadores nos meses mais quentes do ano na região sudoeste do Estado de São Paulo.

\section{MATERAL E METODOS}

O presente ensaio foi conduzido na Unidade de Pesquisa e Desenvolvimento de Itapeva pertencente ao Instituto de Zootecnia do Estado de São Paulo, situado no município de Itapeva, na região sudoeste do Estado, abaixo da linha de Capricórnio. Localiza-se a uma latitude 23058'56"sul e a uma longitude 48052'32" oeste, estando a uma altitude de 684 metros. A temperatura média anual foi de $21,9^{\circ} \mathrm{C}$, a umidade relativa do ar de $76 \%$, e o índice pluviométrico de $1467 \mathrm{~mm}$.

O ensaio foi realizado de outubro a março, abrangendo as duas estações mais quentes do ano verão e primavera. O provimento de calor suplementar foi obtido através da utilização de lâmpada de 250 watts (infravermelha) em altura regulável de 40 a $90 \mathrm{~cm}$ e proporcionando uma área aquecida de 25 a $80 \mathrm{~cm}^{2}$. O isolamento do piso, foi realizado com maravalha (cama de $2,5 \mathrm{~cm}$ de espessura) reduzindo o fluxo do calor condutivo em 66\% (Mount, 1964).

Vinte e quatro porcas primíparas, pertencentes às raças exóticas (Duroc Jersey e Wessex Saddleback), e nativa (Piau Canastra), bem como suas respectivas leitegadas de 8 a 10 leitões ao nascimento e mais de 1,2 quilos de peso vivo/leitão, foram utilizadas. O delineamento experimental adotado foi o de blocos inteiramente casualizados em esquema fatorial $3 \times 2$, segundo Pimentel Gomes (1973). Os fatores foram raça e calor suplementar. Os parâmetros estudados foram sobrevivência dos leitões e peso da leitegada ao 
CASTRO JÚNIOR, F.G.; CAMARGO, J.C.M. e BUDIÑO, F.E.L. Efeito da suplementação de calor para leitões recém-nascidos. PUBVET, Londrina, V. 5, N. 28, Ed. 175, Art. 1178, 2011.

$5^{0}$ dia após o nascimento, bem como o ganho em peso no período. O nível de significância da hipótese nula de rejeição pré-estabelecida foi de $5 \%$.

A lâmpada de aquecimento, foi utilizada neste ensaio até o $3^{\circ}$ dia baseado nos resultados e ou recomendações de Newland et alii (1952), Taylor et alii (1952), Pomeroy (1953), Motte (1968), Zhang \& Xin (2000), e Mendes (2005). As marrãs foram acasaladas aos oito meses de idade, época em que foram sorotipadas para peste suína clássica, e receberam vermífugo a base de tetramisol 1cc. para cada 20 quilos de peso vivo, por via parenteral.

As marrãs durante o período inicial de gestação receberam em média 2 quilos de ração por dia e no terço final, mais 500 gramas, e tiveram acesso a piquetes de grama missioneira [Axonopus compressus(Sw.P.Beauv)] $300 \mathrm{~m}^{2}$ /animal. Para o balanceamento das rações foram seguidas as normas de exigências estabelecidas pelo NRC (1988). As formulações e os ingredientes encontram-se no QUADRO 1.

QUADRO 1. Composição centesimal das rações e seus respectivos ingredientes.

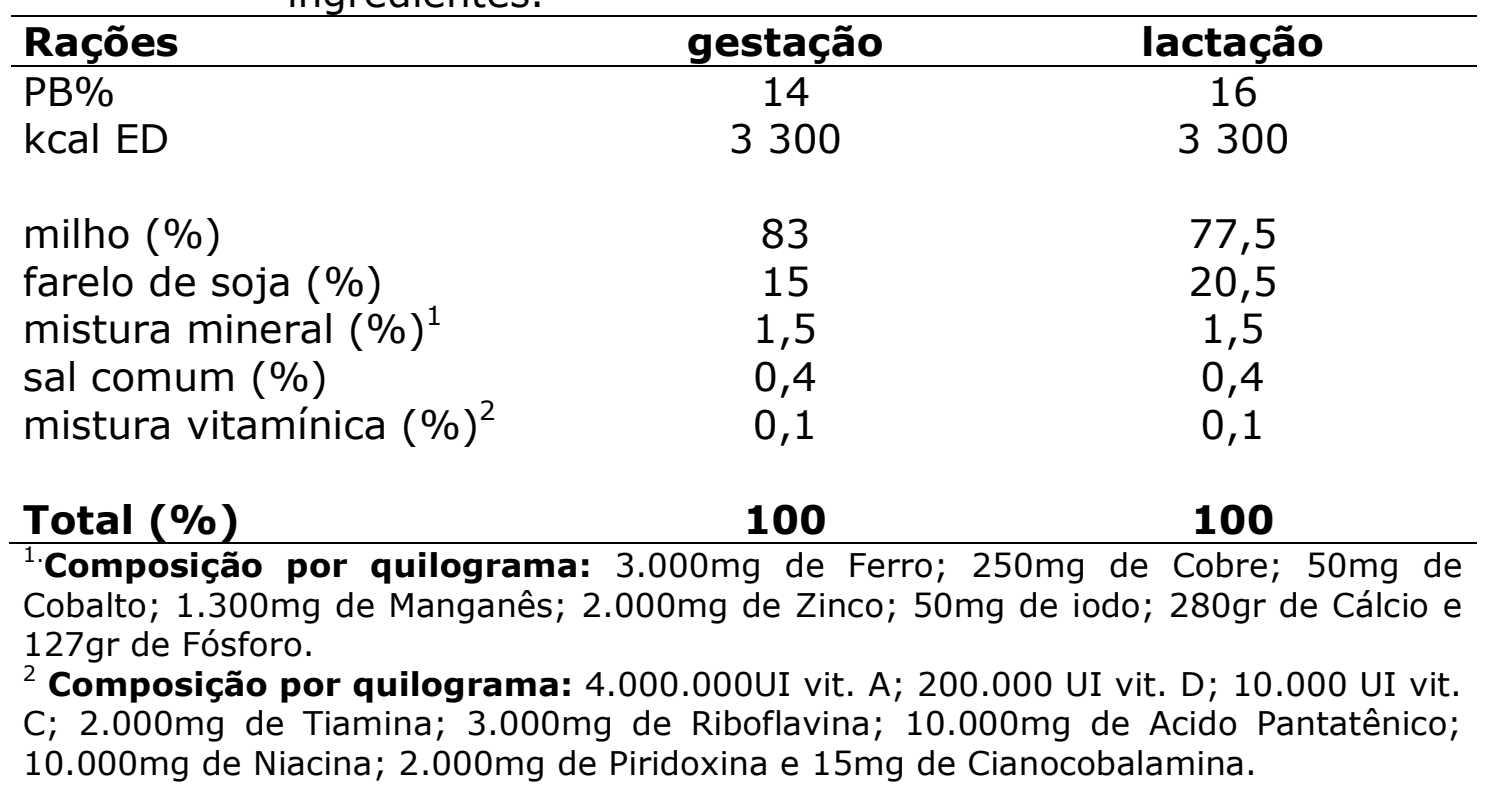

Após o parto as primíparas ficaram em jejum de 24 horas e daí passaram a receber ração gradativamente até atingirem as exigências do NRC (1988). As maternidades foram do tipo tradicional com $7,5 \mathrm{~m}^{2}$ de área, 
CASTRO JÚNIOR, F.G.; CAMARGO, J.C.M. e BUDIÑO, F.E.L. Efeito da suplementação de calor para leitões recém-nascidos. PUBVET, Londrina, V. 5, N. 28, Ed. 175, Art. 1178, 2011.

providas de escamoteador e de ferro protetor de leitões, bem como com cortinas que podem ser observados na FIGURA 1.

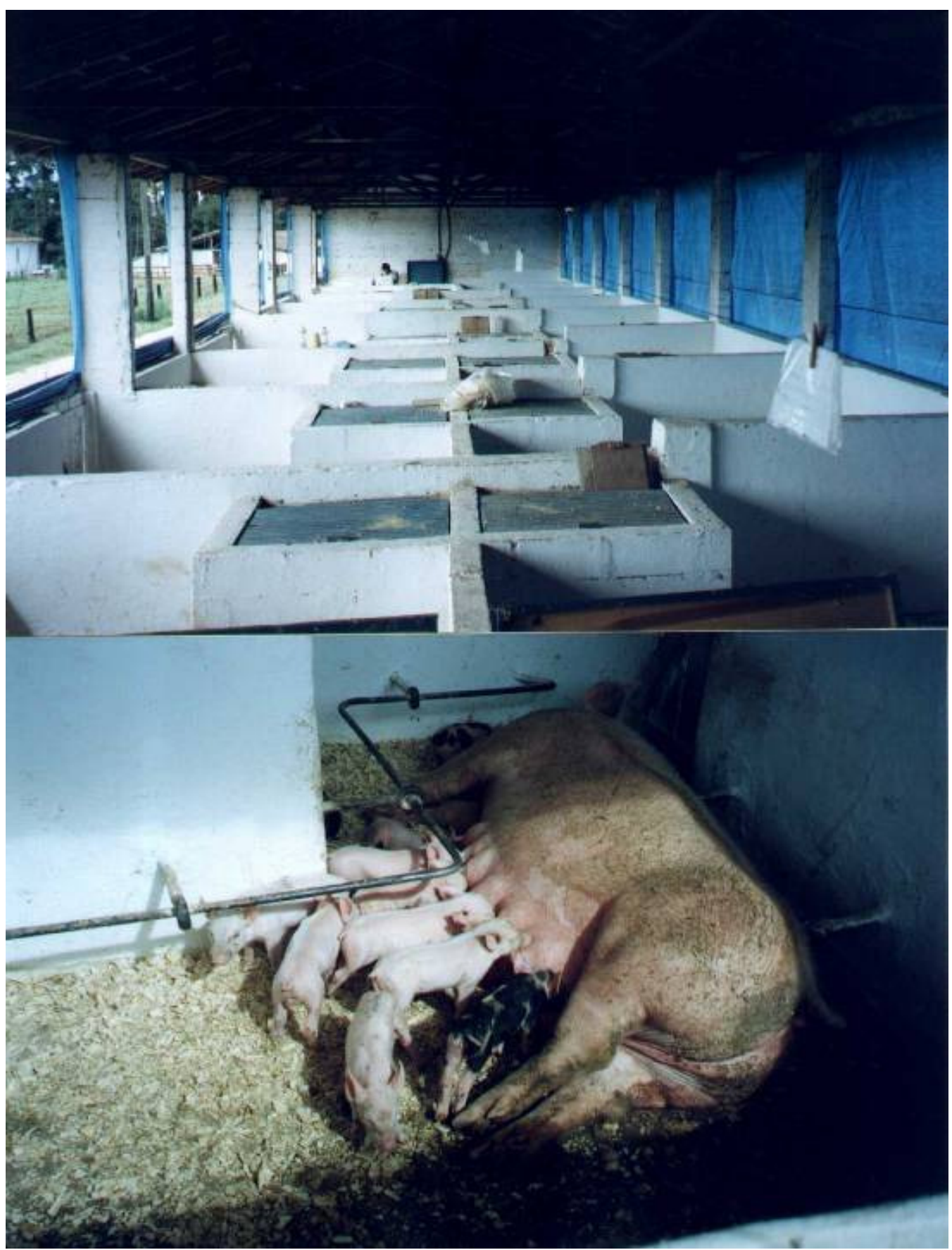

FIGURA 1 Maternidade com escamoteador e ferro protetor dos leitões 
CASTRO JÚNIOR, F.G.; CAMARGO, J.C.M. e BUDIÑO, F.E.L. Efeito da suplementação de calor para leitões recém-nascidos. PUBVET, Londrina, V. 5, N. 28, Ed. 175, Art. 1178, 2011.

\section{RESULTADOS E DISCUSSÃo}

Os dados médios referentes às temperaturas máximas mínimas em ${ }^{\circ} \mathrm{C}$ e da umidade relativa do ar correspondente ao período experimental, são apresentados no QUADRO 2.

QUADRO 2. Temperaturas máximas e mínimas em ${ }^{\circ} \mathrm{C}$ e umidade relativa do ar correspondente ao período experimental.

\begin{tabular}{|c|c|c|c|c|c|c|}
\hline \multirow{2}{*}{ Meses } & outubro & novembro & dezembro & janeiro & fevereiro & março \\
\hline & & & & & & \\
\hline Média & 21,9 & 23,2 & 23,1 & 24,4 & 23,6 & 24,2 \\
\hline Extremas: & & & & & & \\
\hline máxima & 35,4 & 35,6 & 34.8 & 35,8 & 34,0 & 34,0 \\
\hline mínima & 10.4 & 15,0 & 13,0 & 14,4 & 15,4 & 13,2 \\
\hline $\begin{array}{l}\text { média das } \\
\text { máximas }\end{array}$ & 26,2 & 27,0 & 26,0 & 28,5 & 27,9 & 29,1 \\
\hline $\begin{array}{l}\text { média das } \\
\text { mínimas }\end{array}$ & 18,2 & 20,0 & 19,5 & 21,7 & 20,9 & 21,0 \\
\hline $\begin{array}{l}\text { Umidade } \\
\text { relativa do ar } \\
(\%)\end{array}$ & 70 & 75 & 72 & 76 & 79 & 76 \\
\hline
\end{tabular}

Os meses escolhidos representam os mais quentes do ano, a temperatura média mensal do ensaio foi de $23,4^{\circ} \mathrm{C}$ e a umidade relativa do ar de $74,7 \%$, a temperatura máxima foi de $35,8^{\circ} \mathrm{C}$, que ocorreu no mês de janeiro e a temperatura mínima foi de $10,4^{\circ} \mathrm{C}$ ocorrendo em outubro. Entretanto, a média das máximas foi de $27,4^{\circ} \mathrm{C}$ e das mínimas de $20,2^{\circ} \mathrm{C}$. Estes dados são característicos de um clima tropical do tipo savana, de acordo com classificação de Blair, podendo assim representa-lo.

Segundo, Inglaterra (1963) a zona de conforto para os leitões neonatos estaria entre 24 e $27^{\circ} \mathrm{C}$, para Comberg (1966) entre 30 a $32^{\circ} \mathrm{C}$, e para Curtis (1970), baseado em taxas metabólicas ,a temperatura crítica seria de $34^{\circ} \mathrm{C}$. Perdomo (1987) recomendou como temperatura ideal para leitões neonatos $32^{\circ} \mathrm{C}$. 
Baseando-se na média das mínimas, os leitões que não receberam calor suplementar, através da lâmpada de 250 watts infravermelha (que proporcionou uma elevação de temperatura ambiente de $8^{\circ} \mathrm{C}$ ), tiveram a redução da freqüência destes períodos (fora da zona de conforto). Ressaltar ainda a utilização de cama de maravalha (cepilho de madeira), de 2,5 cm. de espessura, que segundo Mount (in Curtis 1970), que reduz o calor condutivo em $66 \%$,(funcionando como um ninho) e todos os leitões experimentais pesaram mais que 1,2 quilos de peso vivo ao nascer (leitões robustos), que segundo Cancelon Martinez (1965) e Blair et alii (1976) são mais resistentes ao frio.

No QUADRO 3 podemos observar a análise de frequência dos leitões sobreviventes no $5^{\circ}$ dia após o parto.

QUADRO 3. Frequência dos leitões sobreviventes no $5^{\circ}$ dia após o parto

\begin{tabular}{lccc}
\hline Tratamentos & $\begin{array}{c}\text { Sem calor } \\
\text { suplementar }\end{array}$ & $\begin{array}{c}\text { Com calor } \\
\text { suplementar }\end{array}$ & Total \\
\hline \multicolumn{1}{c}{ Raças } & & & \\
Duroc Jersey & $31(30,95)$ & $33(33,05)$ & 64 \\
Piau Canastra & $28(27,56)$ & $29(29,44)$ & 57 \\
Wessex & $29(29,49)$ & $32(31,51)$ & 61 \\
Saddleback & & & \\
\multicolumn{1}{c}{ Total } & 88 & 94 & 182 \\
\hline
\end{tabular}

O teste de qui-quadrado para $X^{2}=0,03$ aplicado, mostra que não houve diferenças estatísticas significativas ao nível de $5 \%$ de probabilidade entre os tratamentos (raças e calor suplementar), podendo-se inferir que o número diferente de leitões sobreviventes é devido ao acaso.

Os resultados obtidos neste ensaio, não se alinham com os preconizados por Motte et alii (1968) onde o calor suplementar proporcionou um incremento de até dois leitões desmamados por leitegada. Entretanto, os leitões utilizados no experimento foram mais robustos e o ambiente tipicamente tropical (primavera e verão), o que deve ter favorecido, conforme relato de Bäckström \& Curtis, (1981). 
Os sintomas de resfriamento descritos por Pomeroy (1953) não foram constatados neste ensaio. O não aparecimento destes sintomas poderia ser explicado com a aplicação da equação de Taylor et alii (1952). Se considerarmos $\mathrm{Q}=0$ teríamos $\mathrm{T}=45,45^{\circ} \mathrm{F}$, ou seja, aproximadamente $7,5^{\circ} \mathrm{C}$ e no presente ensaio a temperatura mínima foi de $10,4^{\circ} \mathrm{C}$.

Por outro lado, outros fatores como o isolamento das maternidades com cortinas, conforme preconiza Moraes (2005), bem como a utilização de cama de maravalha ( $2,5 \mathrm{~cm}$ de espessura), a fim de reduzir o fluxo condutivo (Curtis 1970 ) poderiam ter atuado na minimização da perda de calor dos neonatos.

Interações entre temperatura ambiente, umidade relativa do ar, ventilação, isolamento do piso, uso de cortinas, calor dissipado pelos leitões, e reservas energéticas dos mesmos, poderiam ter minimizado os efeitos deletérios da temperatura crítica, preconizada por Curtis (1970), qual seja de $34^{\circ} \mathrm{C}$ para neonatos.

Os dados de desempenho encontram-se sumarizados no QUADRO 4 e a análise estatística no QUADRO 5.

QUADRO 4. Médias do peso ao nascer, ao $5^{\circ}$ dia e ganho de peso das leitegadas até o $5^{\circ}$ dia após o nascimento.

\begin{tabular}{lcccc}
\hline & $\begin{array}{c}\text { No de } \\
\text { leitegadas }\end{array}$ & $\begin{array}{c}\text { Peso médio } \\
\text { inicial }(\mathrm{kg})\end{array}$ & $\begin{array}{c}\text { Peso Médio } \\
\text { final }(\mathrm{kg})\end{array}$ & $\begin{array}{c}\text { Ganho de } \\
\text { peso até o 50 } \\
\text { dia }(\mathrm{kg})\end{array}$ \\
\hline $\begin{array}{l}\text { Raças } \\
\text { Duroc }\end{array}$ & 8 & 14,18 & 14,56 & 0,35 \\
Piau & 8 & 10,95 & 11,07 & 0,12 \\
$\begin{array}{l}\text { Wessex } \\
\text { Fonte } \\
\text { calor }\end{array}$ & 8 & 12,90 & 13,74 & 0,84 \\
Duroc c/luz & & & & \\
Duroc s/luz & 4 & 16,54 & 17,45 & 0,91 \\
Piau c/luz & 4 & 11,87 & 11,67 & $-0,20$ \\
Piau s/luz & 4 & 11,26 & 11,46 & 0,20 \\
Wessex c/luz & 4 & 10,65 & 10,69 & 0,04 \\
Wessex s/luz & 4 & 14,80 & 16,10 & 1,20 \\
& & 11,01 & 11,38 & 0,37 \\
\hline
\end{tabular}


CASTRO JÚNIOR, F.G.; CAMARGO, J.C.M. e BUDIÑO, F.E.L. Efeito da suplementação de calor para leitões recém-nascidos. PUBVET, Londrina, V. 5, N. 28, Ed. 175, Art. 1178, 2011.

QUADRO 5. Análise da variância de ganho em peso até o $5^{\circ}$ dia após o nascimento.

\begin{tabular}{|c|c|c|c|c|}
\hline $\begin{array}{l}\text { Fontes } \\
\text { Variação }\end{array}$ & G.L & $\mathrm{S}, \mathrm{Q}$ & Q.M & $\mathrm{F}$ \\
\hline Raças & 2 & 2,1549 & 1,0825 & $3,98 *$ \\
\hline $\begin{array}{l}\text { calor suplementar } \\
\text { (Duroc) }\end{array}$ & 1 & 2,4465 & 2,4465 & $9,00 *$ \\
\hline $\begin{array}{l}\text { calor suplementar } \\
\text { (Piau) }\end{array}$ & 1 & 0,0054 & 0,0054 & 0,20 \\
\hline $\begin{array}{l}\text { calor suplementar } \\
\text { (Wessex) }\end{array}$ & 1 & 1,7094 & 1,7094 & $6,29 *$ \\
\hline Tratamentos & (5) & 6,3762 & - & - \\
\hline Erro & 18 & - & 0,2717 & - \\
\hline TOTAL & 23 & - & - & - \\
\hline
\end{tabular}

A análise aplicada para ganho em peso até $05^{\circ}$ dia após o nascimento evidenciou, que houve diferenças estatisticamente significativas do efeito do calor suplementar dentro das raças exóticas (Duroc e Wessex) e entre as raças ao nível de $5 \%$ de probabilidade.

As médias do ganho de peso até o $5^{\circ}$ dia para as raças Duroc, Piau e Wessex foram: 0,35, 0,12 e 0,84kg, respectivamente e o desvio padrão de $0,18 \mathrm{~kg}$. A aplicação do teste de Tukey com DMS $=0,665 \mathrm{~kg}$, evidenciou que a raça Wessex foi superior a raça Piau, quanto ao ganho em peso total da leitegada até $05^{0}$ dia após o nascimento. A explicação desta ocorrência poderia estar mais ligada ao fator genético, ou seja, melhor seleção desta raça para ganho de peso da leitegada neste período. Entretanto, embora não significativa, houve uma tendência de superioridade para os parâmetros considerados neste ensaio em favor da raça Wessex, quando comparada a Duroc, principalmente na ausência de calor suplementar, uma vez que a primeira ganhou $0,37, e$ a segunda perdeu $0,20 \mathrm{~kg}$, de peso até o $5^{\circ}$ dia após o nascimento. Este fato poderia ser mais um indicativo da maior capacidade leiteira dos animais pertencentes à raça Wessex.

As leitegadas da raça Duroc que receberam calor suplementar tiveram um ganho de peso até o $5^{\circ}$ dia de $0,91 \mathrm{~kg}$ e as que não o receberam perderam 
CASTRO JÚNIOR, F.G.; CAMARGO, J.C.M. e BUDIÑO, F.E.L. Efeito da suplementação de calor para leitões recém-nascidos. PUBVET, Londrina, V. 5, N. 28, Ed. 175, Art. 1178, 2011.

peso do $0,20 \mathrm{~kg}$. As leitegadas da raça Wessex que receberam calor suplementar, ganharam $1,20 \mathrm{~kg}$ e as que não receberam $0,37 \mathrm{~kg}$. Estas diferenças foram significativas ao nível de $5 \%$ de probabilidade. Entretanto, para a raça nativa Piau Canastra os ganhos de peso foram 0,20 e 0,04kg, esta diferença foi não significativa ao nível de $5 \%$ de probabilidade. Este fato poderia ser explicado se os leitões nativos tivessem apresentado comportamento frente ao resfriamento semelhante aos selvagens do Tennessee, que segundo Foley et alii (1971), que embora menores do que os domesticados, foram mais termoestáveis com seis horas de vida atribuíram este fato a maior proteção do manto piloso, posteriormente, descrito por Blair et alii (1976). Entretanto, os leitões selvagens consumiram mais oxigênio e geraram mais energia para manter a temperatura corporal.

As raças exóticas necessitaram de calor suplementar, conforme recomendações de Newland et alii (1952), Taylor et alii (1952), Pomeroy (1953), Motte (1968), Zhang \& Xin (2000), e Mendes (2005), o que nos permite inferir, que houve mobilização das reservas energéticas descritas por Mount $(1959 ; 1969)$, sendo esta mobilização mais acentuada nos leitões que não receberam calor suplementar. Considerando, que a $20^{\circ} \mathrm{C}$ os leitões tem um incremente de $100 \%$ na perda de calor em relação à $30^{\circ} \mathrm{C}$, Butchbaker \& Shanklin (1964), observaram que a fonte de calor minimizou os efeitos do resfriamento, atuando positivamente no ganho de peso da leitegada, discordando de Adams; Baker; Jesen (1978), que não constataram diferenças de desempenho em leitegadas que receberam calor suplementar até o $3^{\circ}, 6^{\circ} \mathrm{e}$ $21^{\circ}$ dia após o nascimento,

Baseados nos resultados aqui apresentados pode se concluir que as leitegadas das raças exóticas (Duroc e Wessex), que receberam calor suplementar (lâmpada de 250 watts), alojados em escamoteadores com piso de cama de maravalha $\left(2,5 \mathrm{~cm}\right.$ de espessura), ganharam mais peso até o $5^{\circ}$ dia após o nascimento, do que aqueles que não receberam calor suplementar; as leitegadas da raça Piau não demonstraram efeitos positivos no desempenho frente à fonte de calor suplementar e que a utilização de fonte de calor em um 
CASTRO JÚNIOR, F.G.; CAMARGO, J.C.M. e BUDIÑO, F.E.L. Efeito da suplementação de calor para leitões recém-nascidos. PUBVET, Londrina, V. 5, N. 28, Ed. 175, Art. 1178, 2011.

ambiente tipicamente tropical não afetou o número de leitões sobreviventes até o $5^{\circ}$ dia após o nascimento.

\section{REFERÊNCIAS BIBLIOGRÁFICAS}

ADAMS,K.L.;BAKER,T.N.;JENSEN,A.H. Effect of supplemental heat for nursing pigs. In: $70^{\text {th }}$ Annual Meeting of American Society of Animal Science, Michigan State University, U.S.A. 1978. Abstracts..., Albany, N.Y.,1978. p.252

BÄCKSTRÖM, L.; CURTIS, S.E. Housing and environmental influences on production. In: LEMAN, A.D. Diseases of swine. Ames: Iowa State University Press, 737-53, 1981.

BLAIR, L.A.; FJELD, H., STROKAPPE, J.A.; REDDSON, A. Swine production and management. Canada Agriculture,1442: 1-20, 1976.

BUTCHBAKER, A F. \& SHANKLIN, D.M. Partitional heat losses of new born pigs as affected by air temperature, absolutely humidity, age and body weight. Trans ASAE, St. Joseph, Michigan, 7 (4):381-7, 1964

COMBERG, G. Einige Bemerkungen, zum wärmedarf der Ferkel. Schweinezucht Schweinemast, $14(1): 2-3,1966$.

CONCELLON MARTINEZ,A. Porcinocultura: explotación del credos y sus productos. 2 ed. ampl.. Barcelona. Aedos, 1965. 328p.

CURTIS,S.E. Environmental thermoregulatory interactions and neonatal survival. J.Anim.Sci.,Albany, N.Y., 31(3):576-87, 1970.

FOLEY,C.W. et alii. Thermoregulatory responses to cold environment by neonatal and domestic piglets. J. Anim.Sci., Albany,N.Y. 32(5):926-9, 1971.

INGATERRA .Ministry of Agriculture Fisheries and Food. Construcciones para las explotaciones porcinas. Trad. Elias Fernández Gonzales Zaragoza Acribia, 1963. 111p

KELLY, K.W. Environmental effects on the immune system of pigs. Pig News and Information, 3 (4):359-69, 1982.

MENDES,S.A. Efeito do Manejo da Ventilação Natural no Ambiente da Sala de Maternidade para suinos, Piracicaba, Junho- 2005, 89p. (Mestrado). Escola Superior de Agricultura "Luiz de Queiroz", Universidade de São Paulo,

MOUNT, L.E. The metabolic rate of newborn pig in the environmental temperature to age. J. Physiol. , Cambridge, 147:333-45, 1959,

-------, The influence of huddling on the body size on the metabolic rate of the young pig. J.Agric. Sci., Cambridge, 55 (1): 101-5. 1960.

81, 1962.

, Evaporative heat loss in the newborn pig. J. Physiol., Cambridge, 164:274-

-------, Radiant and convective heat loss from the newborn pig. J. Pkysiol. ,Cambridge, 173: 96-101, 1964. 13, 1969.

------, The respiratory quotient in the newborn pig, Br. J. Nutr.,Cambridge, 23:407-

MOTTE, M. et alii. El cerdo: explotación em cochiqueras y al aire libre. 2 ed. ampl. Trad. Julio Gallego Garcia. Madrid, Mundi-Prensa, 1968. 315p. 
NATIONAL RESEARCH COUNCIL (NRC). Committee on Animal Nutrition. Nutrient Requirement of Swine. 10 ed. Washington, D.C., 1998. 189 p.

NEWLAND, H.W. et alii Temperature adaptation in the baby pig. J. Anim.Sci., Albany, N.Y. 11(1): 118-33, 1952.

1973. 430p

PIMENTEL GOMES, F. Curso de estatística experimental 5 ed. São Paulo, Nobel,

PERDOMO, L.C. Avaliação de sistemas de ventilação sobre o condicionamento ambiental e o desempenho de suínos fase de maternidade. Pelotas, 1995. 86p. Tese (Doutorado) Universidade Federal de Pelotas

POMEROY, R. W. Studies on piglet mortality. I. Effect of low temperature and plane of nutrition no the rectal temperature of young pig. J. Agric.Sci., Cambridge, 42(2):182-91, 1953.

SIMMONS, J.R. Keeping piglets warm. Veterinary Record, 98(19):381-2, 1976.

SOBESTIANSKY, J. et alii. Manejo do leitão desde o nascimento até o abate. In: SOBESTIANSKY, J.R.; WENTZ, I.; SILVEIRA, P.R.S.; SESTE, L.A.C. Suinocultura intensiva: produção, manejo e saúde do rebanho. Brasília: EMBRAPA, SPI, Concórdia: EMBRAPA, CNPSA, 1998. cap.7, p.135-161.

TAYLOR, J. G. et alii. Fundamentals of infrared brooding of 'pigs, Agric. Eng.,St . Joseph, Michigan, 33(5):213-15,1952.

ZHANG, Q.; XIN, H. Modeling heat mat operation for piglet creep heating. Transactions of the ASAE, 43 (5):1261-7, 2000. 